\title{
Spatial Distribution of High Current Lightning Discharges in Hokuriku Area in Winter
}

\author{
Mikihisa Saito Member (The University of Tokyo) \\ Masaru Ishii Senior Member (The University of Tokyo) \\ Michihiro Matsui Member (Franklin Japan, Co.) \\ Naoki Itamoto Member (Hokuriku Electric Power Co.)
}

Keywords: lightning, upward lightning discharge, JLDN, winter lightning, LEMP

\section{Introduction}

It is widely known that lightning faults in winter are as many as those in summer on the coastal area of northern Honshu Island along the Sea of Japan. The authors have observed electromagnetic fields associated with lightning discharges on the Fukui Plain in Hokuriku area. The average estimated peak current of lightning discharges observed simultaneously with transmission line faults in winter in this area was about $200 \mathrm{kA}$. In this study, spatial distributions of such high-current lightning discharges around the coastline of the Sea of Japan in winter are examined with the help of data observed by JLDN (Japanese Lightning Detection Network) and a network of fast antennas (FA) on Fukui Plain.

\section{Observation}

274 negative and 216 positive lightning discharges with estimated absolute peak currents of higher than $60 \mathrm{kA}$, simultaneously recorded by JLDN and the FA network are analyzed. The observation periods for negative discharges are December and January from 2001 to 2005. Positive discharges are data obtained during November 2001 to January 2002.

Electric field waveforms observed simultaneously with transmimission line faults, especially those having the same polarity as negative cloud-to-ground (CG) return strokes, had distinct characteristics. It is inferred that they are produced by upward flashes, and the corresponding lightning stroke is expressed as -GC (Groundto-Cloud flash) in this paper. +GC can also be identified from the associated electric field waveform.

Figure 1 shows a spatial distribution of examined negative highcurrent lightning discharges. Almost all the $-\mathrm{GC}$ are on land, whereas -CG of high current, showing similar electric field waveforms commonly observed in summer, distribute evenly over sea and land. Figure 2 shows a spatial distribution of examined positive high-current lightning discharges in winter. Different from the spatial distribution of negative high-current discharges, positive highcurrent discharges distribute also over the sea.

\section{Conclusion}

Electric field waveforms associated with high-current lightning

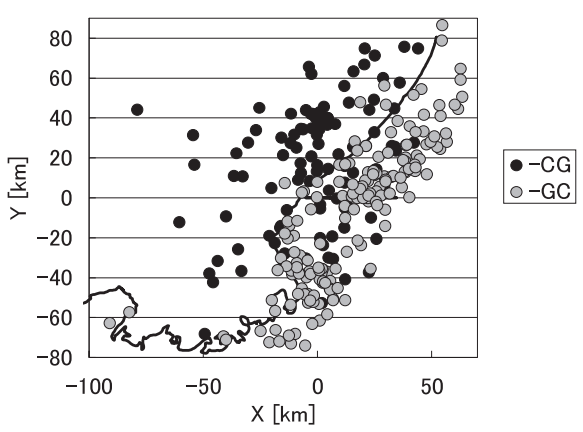

Fig. 1. Spatial distribution of lightning discharges with negative high current in winter

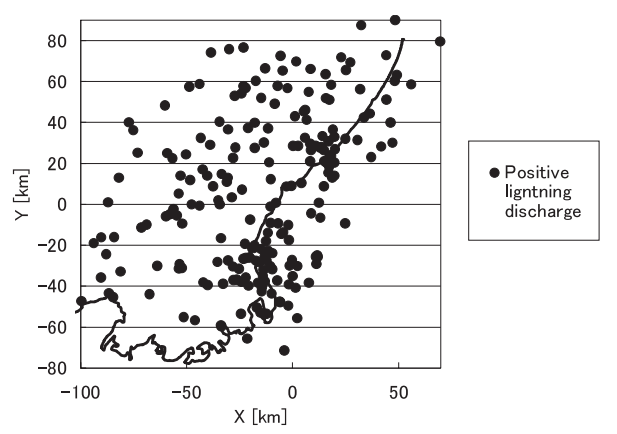

Fig. 2. Spatial distribution of lightning discharges with positive high currents in winter

discharges in winter in Hokuriku area are analyzed. The density of negative high-current lightning flashes over land in December and January was about 4 times as many as that over the sea. Majority of negative high-current lighting flashes are inferred upward flashes. In contrast, there is not clear difference in the spatial distributions of positive high-current discharges between those over the sea or on land. 


\title{
Spatial Distribution of High Current Lightning Discharges in Hokuriku Area in Winter
}

\author{
Mikihisa Saito* Member \\ Masaru Ishii* Senior Member \\ Michihiro Matsui ${ }^{* *}$ Member \\ Naoki Itamoto ${ }^{* * *}$ Member
}

\begin{abstract}
The electric field waveforms associated with lightning discharges that were observed simultaneously with faults of power transmission lines in winter are analyzed. Also, electric field waveforms associated with high current lightning discharges in winter around the coastline of the Sea of Japan are analyzed for comparison. All of the negative lightning discharges simultaneously observed with transmission line faults produced different field waveforms from those produced by normal cloud-to-ground strokes. Positive high-current lightning discharges, however, produce field waveforms which look more like those produced by normal cloud-to-ground strokes. These high-current lightning discharges distribute differently around the coastline depending on their polarities.
\end{abstract}

Keywords: lightning, upward lightning discharge, JLDN, winter lightning, LEMP

\section{Introduction}

It is widely known that lightning faults in winter are as many as those in summer on the coastal area of northern Honshu Island along the Sea of Japan. The authors have observed electromagnetic fields associated with lightning discharges on the Fukui Plain in Hokuriku area. The average estimated peak current of lightning discharges observed simultaneously with transmission line faults in winter in this area was about $200 \mathrm{kA}^{(1)}$. In this study, spatial distributions of such highcurrent lightning discharges around the coastline of the Sea of Japan in winter are examined with the help of data observed by JLDN (Japanese Lightning Detection Network) and a network of fast antennas (FA) on Fukui Plain ${ }^{(2)}$. A fast antenna is a device to observe fast electric field change in wide band by using an electrostatic antenna. Features of field waveforms of such high-current lightning discharges observed by a fast antenna are also discussed.

\section{Observation}

JLDN is a large-scale single lightning detection network covering the whole area of Japan, operated by Franklin Japan Co. It observes LEMP (lightning electromagnetic impulse) in the frequency range from VLF to LF, and estimates location and current amplitudes of lighting strokes ${ }^{(2)}$. Records of LEMP over Fukui Plain, captured by JLDN, are compared with records of electric field waveforms observed by the FA network ${ }^{(2)}$. The observed frequency range by the FA was $0.32 \mathrm{kHz} \sim 1.2 \mathrm{MHz}$.

\footnotetext{
* The University of Tokyo

4-6-1, Komaba, Meguro-ku, Tokyo 153-8505

** Franklin Japan Corporation

1-1-12, Miyashimo, Sagamihara 229-112

*** Hokuriku Electric Power Co.

2-54, Hisakata-machi, Toyama 930-0848
}

In this paper, lightning discharges which produce electric field waveforms having the same initial polarity as those from positive return strokes are named positive discharges. Those in the opposite polarity are negative discharges. The empirical relationship between the peaks of range-normalized magnetic field strength and the lighting current amplitude, employed by JLDN to estimate lightning peak currents, may not be applied to those high-current lightning discharges in winter, however, the estimated peak-current value by JLDN, which is basically proportional to the range-normalized magnetic field peak, is adopted to indicate the current magnitude of a lightning discharge.

274 negative and 216 positive lightning discharges with estimated absolute peak currents of higher than $60 \mathrm{kA}$, simultaneously recorded by JLDN and the FA network are analyzed. The observation periods for negative discharges are December and January from 2001 to 2005. Positive discharges are data obtained during November 2001 to January 2002.

Because the estimated currents of lightning discharges observed simultaneously with transmission line faults were $60 \mathrm{kA}$ or higher, therefore, $60 \mathrm{kA}$ is adopted as a threshold of large current. Figure 1 shows the observation area, which is fully covered by JLDN. Because of the low sensitivity of the FA network, it does not cover the northwest corner of the observation area. The blanc area in the southeast corner of Fig. 1 is excluded from the analysis, since there were few lightning discharges in winter.

Total number of negative discharges including in-cloud (IC) discharges in this area, captured by JLDN during the observation period, was about 20000. The number of lightning discharges with current magnitudes higher than $-60 \mathrm{kA}$ is about 1200. Among them, 274 discharges simultaneously observed by the FA network are subject to analysis. Few too complex waveforms were excluded; nevertheless, still 39 data out of 274 were discriminated as IC by JLDN. 


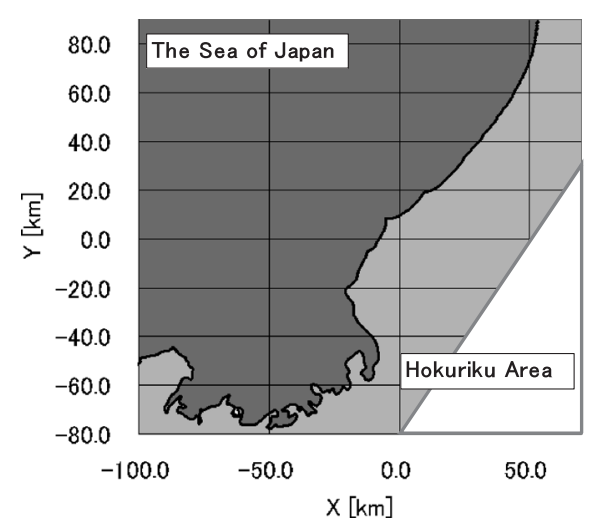

Fig. 1. Observation area

Total number of positive discharges similarly captured by JLDN was about 4500 . The number of lightning discharges with current magnitudes higher than $+60 \mathrm{kA}$ is about 800 . Among them, 213 discharges simultaneously observed by the FA network are subject to analysis. Here also, few too complex waveforms are eliminated. All the 213 data were discriminated by JLDN as cloud-to-ground (CG) lightning strokes.

\section{Negative Lightning Discharges}

Figure 2 shows an example of the electric field waveform produced by a negative high-current discharge, inferred an upward lightning discharge ${ }^{(1)(3)}$. All the 21 negative lightning discharges observed simultaneously with power line faults produced this type of electric field waveform.

As seen in Fig. 2, electric field waveforms produced by this type of negative lightning discharges, expressed as -GC (Ground-to-Cloud flash) in this paper, are preceded by several bipolar pulses before the main peak; fast transition and slow-front are not clear; few pulses superpose the rising part of the main peak; the amplitude of the peak of the opposite polarity after the main peak is large; the zero-crossing time from the main peak is shorter than that of normal -CG waveforms; and duration of VHF radiation before and after the main peak is shorter than that of normal $-\mathrm{CG}$ waveforms. The duration of VHF radiation before and after the main peak of a normal -CG waveform is more than several milliseconds each, in contrast to that from $-\mathrm{GC}$, which is within $0.5 \mathrm{~ms}$ each. These features are prominent, and are not difficult to identify.

Figure 3 shows a spatial distribution of examined 274 negative high-current lightning discharges. Few -GC located on the sea by JLDN may involve large location error, and their true location may be on land. Because field waveforms produced by $-\mathrm{GC}$ are different from those of normal -CG, location error tends to be larger than that of normal -CG. Almost all the $-\mathrm{GC}$ are on land, whereas -CG of high current, showing similar electric field waveforms commonly observed in summer, distribute evenly over the sea and land.

From Fig. 3, only about $1 / 4$ of negative high-current lightning discharges are known to be located on the sea. Figure 4 shows the yearly variation of the numbers of negative flashes with estimated absolute peak currents higher than $-60 \mathrm{kA}$, observed by JLDN. during December and January. In terms of the lightning flash density, an average of that over 5 years

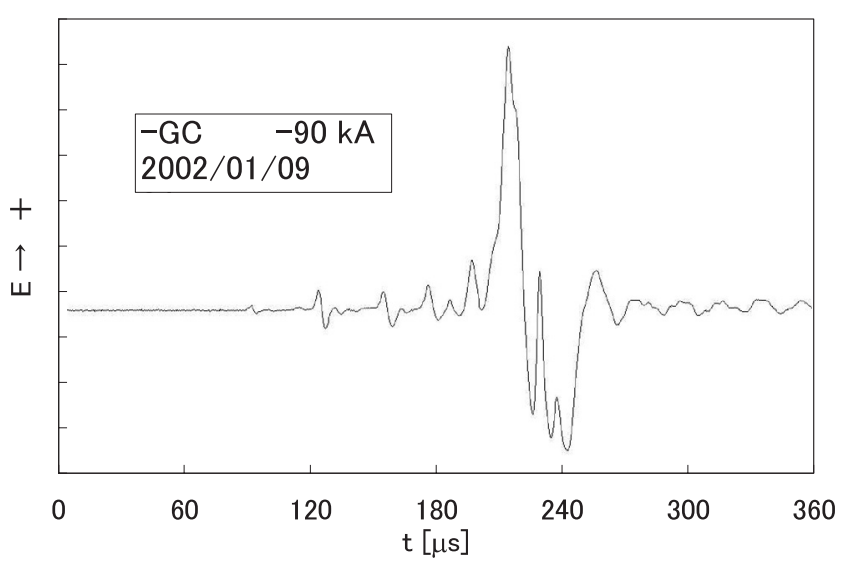

Fig. 2. Example of electric field waveform associated with upward lightning discharge of negative high current in winter

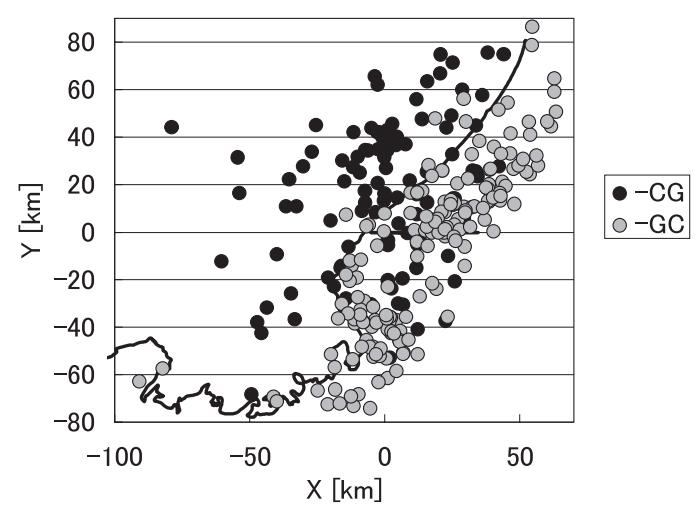

Fig. 3. Spatial distribution of lightning discharges with negative high current in winter

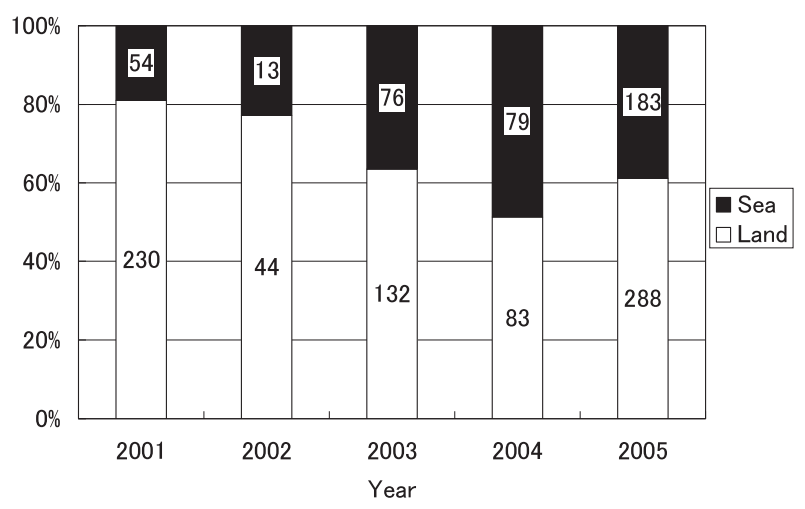

Fig. 4. Annual variation of numbers of high-current negative flashes on sea and land in winter

on land was about 4 times of the flash density over the sea for negative high-current discharges.

The spatial distribution of negative lightning discharges with smaller currents differs. Figure 5 shows the contour lines of topography and location of 5800 negative lightning discharges detected by JLDN during December 2001 and January 2002.

About 1000 strokes out of 5800 were discriminated as incloud discharges by JLDN. The lightning stroke density of all strokes over land close to the coastline was still twice as high as that over the sea, however, the difference in the stroke densities between those over the sea and land is much smaller 


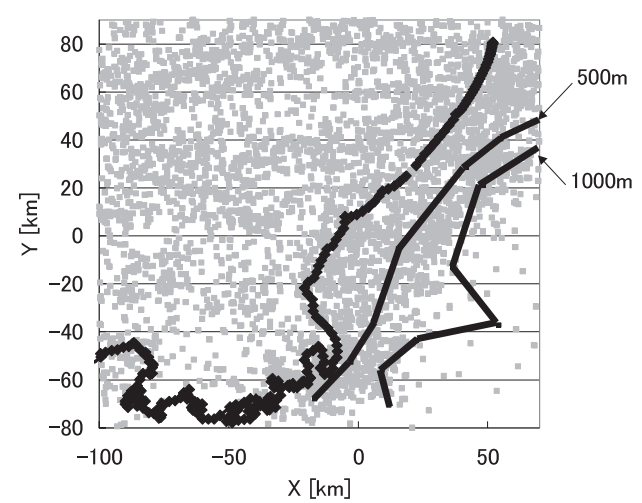

Fig. 5. Distribution of all the negative lightning discharges relative to coastline and contour lines (Dec. 2001 Jan. 2002)

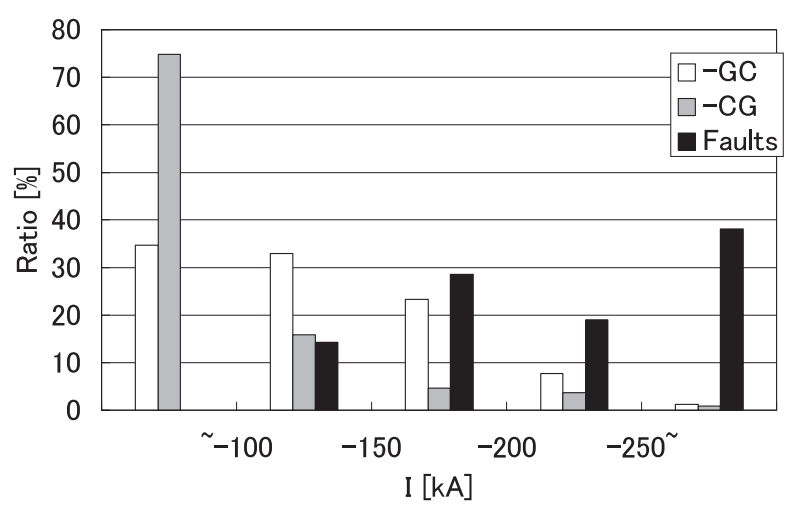

Fig. 6. Normalized distribution of negative lightning currents in winter observed by JLDN

than for high-current lightning discharges. More than about $40 \mathrm{~km}$ inland or at higher altitudes than about $1000 \mathrm{~m}$, the stroke density abruptly decreases.

Figure 6 shows distributions of currents for the examined 274 high-current negative discharges, subdivided into 167 -GCs and 107 -CGs. Additionally, it also shows the 21 data observed simultaneously with transmission line faults ${ }^{(3)}$. Discharges in distances farther than about $85 \mathrm{~km}$ with currents lower than $-100 \mathrm{kA}$ may not have been detected by the FA network, as its sensitivity is relatively low. It is obvious, however, that the average of peak magnetic fields associated with -GC strokes is much higher than that associated with normal $-\mathrm{CG}$ strokes in winter.

The all 21 electric field waveforms simultaneously observed with transmission line faults were all those of -GC. Since only high pulse currents injected into transmission lines can cause faults, the lower end of the current distribution for these 21 data lies above $-100 \mathrm{kA}$ level. It is obvious that this distribution is a part of the current distribution for -GC. It is also inferred that these $21-\mathrm{GC}$ field waveforms are associated with upward lightning discharges ${ }^{(3)}$.

Based on the above result, it is concluded that majority of high-current negative lightning discharges observed on the coastal area facing the Sea of Japan in winter are upward discharges. They are observed seldom over the sea.

\section{Positive Lightning Discharges}

Figure 7 shows spatial distribution of the 213 positive

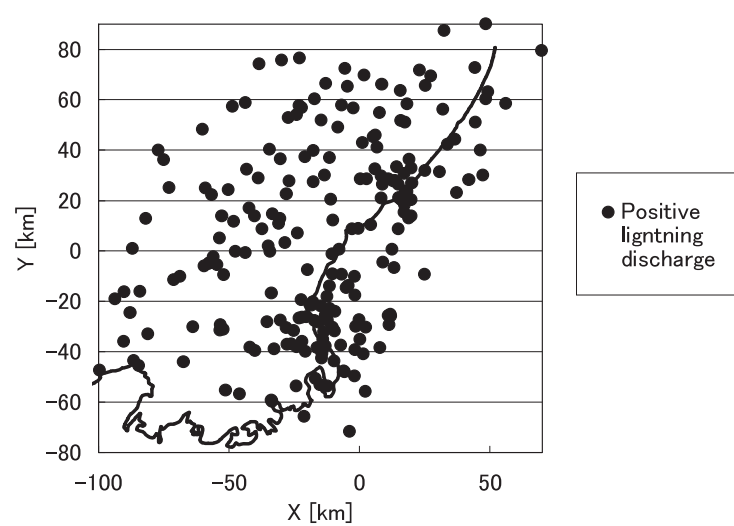

Fig. 7. Spatial distribution of lightning discharges with positive high current in winter

high-current lightning discharges in winter. Different from the spatial distribution of negative high-current discharges, positive high-current discharges distribute also over the sea. The blanc area in the northwest corner over the sea is due to the low detection efficiency of the FA network. The spatial distribution over land is similar to that of negative highcurrent discharges. The spatial distribution of all the positive strokes detected by JLDN in the same observation period is similar to Fig. 5, so it is not shown here.

Electric field waveforms associated with positive lightning discharges simultaneously observed with transmission line faults, which has different features from field waveforms associated with positive return strokes, have been collected. Different from negative high-current discharges, it is hard to find clear distinction, upward or downward, for electric field waveforms associated with positive high-current lightning discharges in winter ${ }^{(4)}$.

One of the features of electric field waveforms simultaneously recorded with transmission line faults is that the rising part of the main peak neither shows fast transition nor smooth slow front, as is not seen in the example of Fig. 8(a), in contrast to the waveform of a normal positive return stroke in Fig. 8(b). This difference results in the tendency of longer rise times of the main peak of the field waveforms, associated with inferred upward positive lightning discharges, than those of normal positive return strokes. Therefore, duration of the rising part of the main peaks is investigated.

To be less influenced by the propagation effect on the electromagnetic field waveform over land of finite conductivity in evaluating the rise time, 61 positive high-current discharges, in the range from 35 to $55 \mathrm{~km}$ from a fast antenna, are selected for analysis. 11 data simultaneously observed with transmission line faults in the same range are added to the data set.

$10-90 \%$ rise time ${ }^{(5)}$ or $0-100 \%$ rise time ${ }^{(6)}$ of positive return strokes had been examined, however, due to the irregularity of the shape of the rising part of those field waveforms like Fig. 8(a), 10-100\% rise time, which is less influenced by the irregularity, is evaluated. The first peak, which is defined as the first peak higher than $50 \%$ of the amplitude of the LEMP, is chosen as the $100 \%$ point among the multiple peaks of a complex waveform. 10-100\% rise time can be compared with 10-90\% rise time of a waveform having a smooth rising part. 


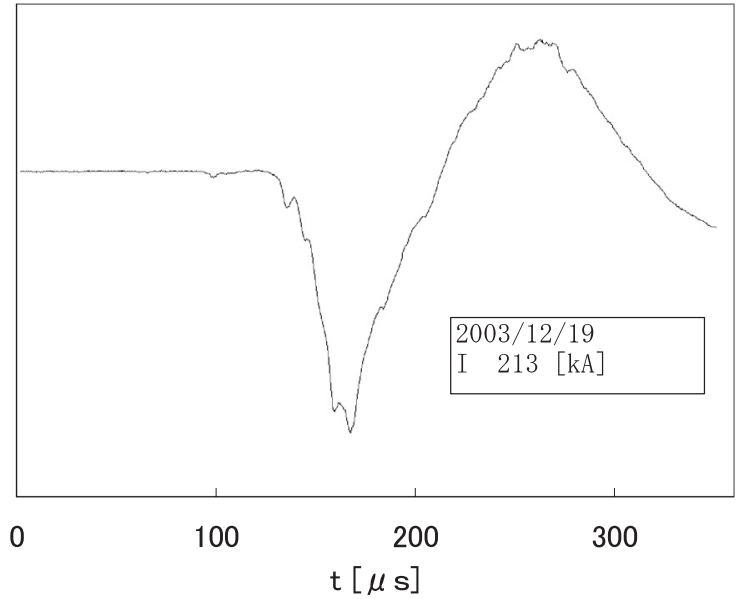

(a) $2003 / 12 / 19213 \mathrm{kA} 50 \mathrm{~km}$

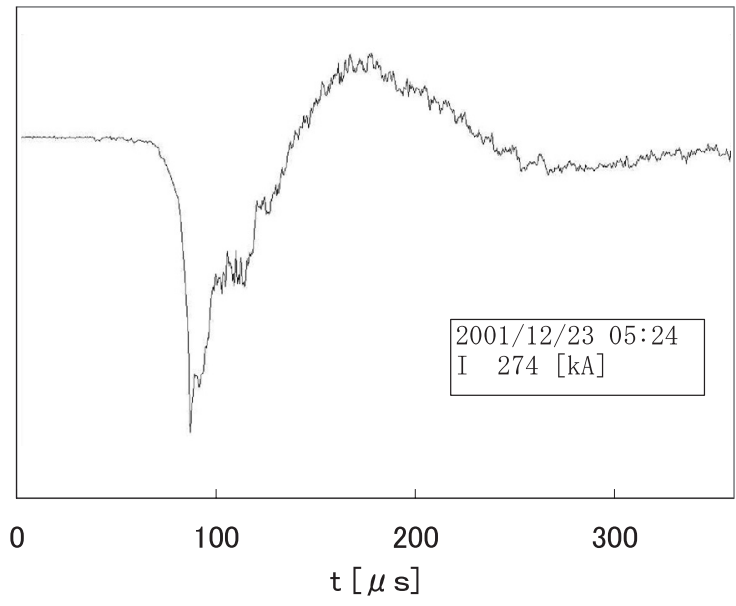

(b) $2001 / 12 / 23274 \mathrm{kA} 40 \mathrm{~km}$

Fig. 8. Examples of electric field waveform associated with inferred upward positive GC stroke (a) and that with positive return stroke (b)

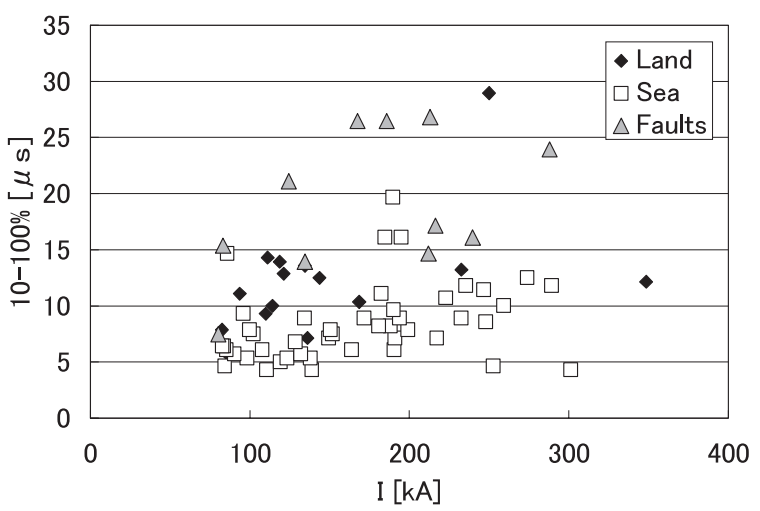

Fig. 9. 10-100\% rise time and range-normalized magnetic field amplitude, expressed in $\mathrm{kA}$, of field waveforms of positive discharges in winter

The 61 positive discharges are subdivided into two groups over the sea and land. The combination of $10-100 \%$ rise time and range-normalized magnetic field amplitude, expressed in $\mathrm{kA}$, of individual field waveforms in the three groups of positive discharges in winter, including those associated with transmission line faults are shown in Fig. 9.

There is positive correlation between the range-normalized peak magnetic field and the rise time, as was mentioned for field waveforms of negative return strokes ${ }^{(7)}$. An important feature is that the three groups of positive discharge waveforms, namely observed over the sea, over land or simultaneously observed with transmission line faults, have different characteristics each other in the relationships between the peak range-normalized field and the rise time. Those associated with transmission line faults form a group having long rise times, mostly longer than $13 \mathrm{~ms}$. Those observed over the sea form a compact group having short rise times mostly shorter than $13 \mathrm{~ms}$. The group of waveforms observed over land lies in between of the other two groups.

\section{Discussion}

Most of the negative high-current discharges were observed on land, and it is concluded that they are initiated by upward leaders. These negative upward flashes seldom occur over the sea. The field waveforms associated with negative upward flashes with negative high current in winter can be distinguished from normal negative return-stroke waveforms, even after influenced by the propagation effect over land. It is inferred that such distinct difference between the field waveforms from an upward high-current negative flash and a negative return stroke is due to the distinct difference in the geometrical structure of the lightning channels. A simple bipolar radiation waveform like that of Fig. 2 strongly indicates that the the lengths of the lightning channels in the cloud are short $^{(8)}$, in contrast to the extensive horizontal channels in the cloud for a normal return stroke.

Observed VHF radiation ${ }^{(3)}$ agrees to the above inference. $\mathrm{VHF}$ radiation from negative leaders are stronger than that from positive leaders, and easier to detect, however, no VHF radiation was observed until several hundreds of microseconds before the main pulse of the field waveform of a negative high-current discharge. This indicates that negative leaders in the cloud connected to negative charges extended for only several hundreds of microseconds before the main pulse of the discharge, therefore, the lengths of discharge channels in the cloud had to be short. In such a case, the channel connecting the cloud and ground is formed by a positive upward leader from ground, whose VHF radiation is detectable only from a close range ${ }^{(3)}$. Normal return strokes, on the other hand, are preceded by VHF radiation, presumably from negative leaders, for more than a few $\mathrm{ms}$ in the cloud before the formation of a downward stepped leader ${ }^{(3)}$.

In the waveforms of positive lightning discharges simultaneously observed with transmission line faults, which are inferred upward flashes, there is difference in the rising part of the main pulses from that of normal positive return stroke waveforms, however, this difference is obscured after propagation of the LEMP over land. There is not distinct difference in the wave tails of the positive waveforms, which is reflected by the outputs of JLDN that all the analyzed positive high-current discharges, including those associated with transmission line faults, were interpreted as CG strokes.

There is difference in the duration of the $10-100 \%$ rise time of waveforms associated with inferred positive upward flashes and those with positive discharges over the sea, although there is overlap of the lower and upper ends of the respective distributions of the rise time. It is likely that most of positive ground flashes over the sea are normal 
positive downward flashes. Resemblance of wave tails of these field waveforms, however, indicates that the geometrical structures of lightning channels of positive high-current discharges are similar for both upward and downward flashes. This inference agrees to the observation of VHF radiation ${ }^{(4)}$, that positive discharges simultaneously observed with transmission line faults initiate in cloud like normal +CG flashes, and then they trigger upward leaders from ground.

The positive high-current discharges observed over land show characteristics between the above-mentioned two groups of positive discharges. If there is no fundamental difference in the geometrical structure of lightning channels between the positive upward and downward flashes in winter, the duration of the rise time of the field waveform may indicate the length of an upward leader, which may have more variant lengths at discharges over land than those over the sea.

\section{Conclusion}

Electric field waveforms associated with high-current lightning discharges in winter in Hokuriku area are analyzed. On land, most of them occur within about $40 \mathrm{~km}$ from the coastline and below about $1000 \mathrm{~m}$ of altitude, similar to lowcurrent lightning discharges. Different characteristics in the spatial distributions are found between those of the positive and negative high-current discharges over the sea.

The 5-year average density of negative high-current lightning flashes over land in December and January was about 4 times as many as that over the sea. $80 \%$ of observed highcurrent negative discharges over land were upward flashes in the winter, which can be distinguished by the field waveform of the LEMP from that of normal negative return strokes.

In contrast, there is not clear difference in the spatial distributions of positive high-current discharges between those over the sea or on land. In the field waveforms also, there is not clear difference between those associated with upward or downward initiated high-current lightning discharges. In the $10-100 \%$ rise time, however, there is distinct difference between the distribution for positive high-current discharges associated with transmission line faults and that for those over the sea.

High-current lightning discharges associated with transmission line faults are inferred upward lightning flashes; therefore, it is also inferred that the main pulse of the field waveform of a positive high-current upward flash has generally longer rise time than that of a positive return stroke waveform of similar peak current.

(Manuscript received March 27, 2007,

revised Aug. 10, 2007)

\section{References}

( 1 ) M. Ishii, M. Saito, F. Fujii, M. Matsui, and N. Itamoto: "High current lightning discharges in winter", 18th Annual Conference of Power \& Energy Society, IEE Japan, 77 (2007) (in Japanese)

( 2 ) M. Ishii., M. Saito, F. Fujii, J. Hojo, M. Matsui, N. Itamoto, and K. Shinjo: "LEMP from lightning discharges observed by JLDN", IEEJ Trans. PE, Vol.125, No.8, pp.765-770 (2005)
( 3 ) M. Ishii, M. Saito, and N. Itamoto: "Electric field waveforms associated with high-current lightning discharges in winter", The Papers of Technical Meeting on High Voltage Engineering, IEE Japan, HV-05-47 (2005) (in Japanese)

( 4 ) M. Ishii, M. Saito, and N. Itamoto: "High-current positive lightning discharges in winter", The Papers of Technical Meeting on High Voltage Engineering, IEE Japan, HV-06-47 (2006) (in Japanese)

( 5 ) J. Hojo, M. Ishii, T. Kawamura, and F. Suzuki: "The fine structure in the field change produced by positive ground strokes", J. Geophys. Res., Vol.90, No.D4, pp.6139-6143 (1985)

( 6 ) M. Ishii and J. Hojo: "Statistics of fine structure of cloud-to-ground lightning field waveforms", J. Geophys. Res., Vol.94, No.D11, pp.13267-13274 (1989)

( 7 ) Lightning and Insulator Subcommittee of the T \& D Committee of IEEE: "Parameter of lightning strokes: a review", IEEE Trans. Power Delivery, Vol.20, No.1, pp.346-358 (2005)

( 8 ) M. Ishii, M. Saito, and N. Itamoto: "High current upward lightning flashes in winter", 13th Int. Conf. on Atmospheric Electricity, OS4-2, Beijing (2007)

Mikihisa Saito (Member) was born in Chiba, Japan, on September 19,

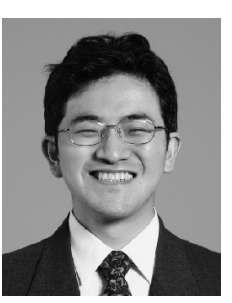
1972. He received B.S. in Instrumentation engineering from Keio University in 1997 . He joined Institute of Industrial Science, the University of Tokyo in 1999. Now he is a Technical Associate. He has been engaged mainly in the study of lightning phenomena.

Masaru Ishii (Senior Member) was born in Tokyo, Japan, and re-

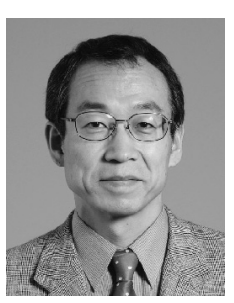
ceived B.S., M.S. and Ph.D degrees in electrical engineering all from the University of Tokyo in 1971, 1973 and 1976, respectively. He joined Institute of Industrial Science, the University of Tokyo in 1976, and has been a Professor since 1992 . His specialty is high voltage engineering. He is a Vice President of IEE of Japan for 2007-2008, and the convener of CIGRE Advisory Group C4.4 (Lightning). Dr. Ishii is a Fellow of IEEE and a member of AGU and CIGRE.

Michihiro Matsui (Member) was born in Kanagawa, Japan, on April

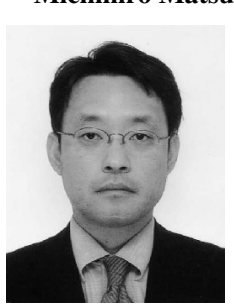
2nd, 1968. He received B.Eng. degree in electric and electronic engineering from Musashi Institute of Technology in 1991. He joined Franklin Japan Co. in 1998. Now he is the manager of the Engineering Department. He has been engaged mainly in the development of application software for thunderstorm forecast.

Naoki Itamoto (Member) was born in Toyama, Japan, on February

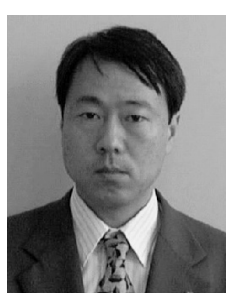
17, 1957. He received B.S. in electronic engineering in 1980, and Ph.D. in electrical engineering in 2000, both from Kanazawa University. He joined Hokuriku Electric Power Company in 1980. Now he is a senior researcher of Engineering Research \& Development Center. He has been engaged mainly in the lightning protection design for substations and transmission systems. 